\title{
TRANSMISSION OF RISK ACROSS STOCK MARKETS IN LATIN AMERICA
}

\author{
Tapen Sinha* \\ Instituto Tecnológico Autónomo de México \\ María de los Dolores Sánchez Castañeda
}

University of Oxford

(Received 27 may 2002, accepted 26 september 2002)

\begin{abstract}
In the folklore, it is generally accepted that all the Latin American stock markets suffered as a result of the crisis of the Mexican economy during 1994-1995. The media coined a name for it: "tequila effect". This well accepted "folk theory" implicitly assumes the stock markets in the world are in fact integrated and the risk transmission mechanism is well understood. In this investigation, we examine the transmission mechanism in a well-defined statistical sense (Granger causality). We develop methods for measuring the transmission mechanism. We also examine the relationship among some stock markets using daily data for Latin American countries (such as Argentina, Brazil, Colombia, Chile, Mexico and Venezuela) of stock market indexes between 1994 and 1998. This period contains several large upheavals in the market indexes for many of the Latin American countries. Our results of Granger causality uncover many relationships very clearly.
\end{abstract}

\section{Resumen}

En el argot se acepta generalmente que todos los mercados accionarios de America Latina se vieron afectados como resultado de la crisis que se presentó en la economía mexicana durante 1994-1995. Los medios acuñaron un nombre para este fenómeno: "efecto tequila". Esta "denominación popular" supone implícitamente que los mercados accionarios en el mundo están integrados y el mecanismo de transmisión del riesgo es perfecto. En este trabajo, primero estudiamos el mecanismo de la transmisión en un sentido estadístico perfectamente definido (causalidad de Granger). En segundo lugar, se desarrollan los métodos para medir el mecanismo de dicha transmisión. En tercer lugar, analizamos la relación que existe entre los mercados de acciones con base en datos diarios (Argentina, Brasil, Colombia, Chile, México y Venezuela) de los índices de los mercados accionarios latinoamericanos entre 1994 y 1998. Este periodo se caracteriza por las grandes variaciones en los índices de mercado para muchos de los países latinoamericanos. Nuestros resultados de causalidad de Granger muestran que claramente existen relaciones muy fuertes.

JEL classification: 663

Keywords: Cointegration

* Department of Actuarial Studies, Instituto Tecnológico Autónomo de México (ITAM), Río Hondo 1, Tizapan, San Angel, C.P. 01000 México, D.F. Telephone (52) 56284088,Fax (52) 56284086 E mail:tapen@itam,mx

The authors are grateful to the anonymous referees for their comments. 


\section{Introduction}

There is a general belief that stock markets in the world are closely related. Consider the recent economic crisis in Brazil or Russia. Newspapers were full of reports stating that such crisis where the causes of stock market falls all over the world. In 1997-1998, we heard the same about how Asian stock market performance (as well as economic performance) was putting a damper on the world stock markets. In the folklore it is accepted that all the Latin American stock markets suffered as a result of the crisis of the Mexican economy during 1994-1995. The media coined a name for it: the "tequila effect".

This implicitly well accepted folk theory presumes that the world stock markets are in fact well integrated and the risk transmission mechanisms are well understood. If so, there would hardly be any point in international diversification of portfolios. Moreover, there would be no reason why Wall Street would be setting record after record when Tokyo stock market is languishing. This phenomenon is not new. In 1987, when most of the world stock markets collapsed, Tokyo market shrugged it off and went on to set new highs. Two years later, Tokyo stock market crashed and it does not look like it will recover so soon. Meanwhile, other markets have taken different trajectories.

Thus, generally, there is no obvious relationship between any pair of stock markets. There have been a number of studies examining the relationship between stock markets in developed countries. However, studies examining relationship between the stock markets of developed and developing countries are sparse. Our contribution here is to explicitly study the relationship between the stock markets of the Latin American countries and that of the developed countries.

Studies of stock market relationship studies fall in the following broad categories: (1) studies that look at daily data, (2) studies that look at monthly data; (3) studies that explore relationship between the stock market indices, (4) studies that explore relationship between rates of returns; (5) studies that take stock market indices themselves, (6) studies that convert the indices into a single currency by multiplying the indices by the contemporary exchange rate.

\section{Review of literature}

A number of researchers have studied the transmission mechanism of relations between stock markets. The study that stimulated a lot of interest was that of Malliaris and Urrutia (1992). Their study was to explore what happened around the 1987 stock market crash. They studied pairs of countries to examine how daily rates of return between the US, UK, Japan, Australia, Singapore and Hong Kong markets were related during one year around the $1987 \mathrm{crash}$ through Granger causality tests. They found bidirectional causality between 1) US and UK, 2) US and Hong Kong, 3) UK and Singapore, 4) UK and Japan, 5) UK and Australia and 6) Japan and Australia. On the other hand, there were many 
unidirectional relationships: 1) from the US to Japan, 2) from UK to Hong Kong, 3) from Hong Kong to Singapore, 4) from Japan to Singapore, 5) from Australia to Singapore, and 6) from Hong Kong to Japan. Note that this study was focussed exclusively on what happens around the time of a global stock market crash. This study did not explore block causality.

Recent papers have focused on other aspects of the crash such as the volatility of the markets during the crash of 1987. For example, Najand (1996) uses a state-space approach over a longer horizon (1984-89) to study the 1987 crash. Studies of European countries also reveal some causal relationship between the stock markets there. Specifically, UK has a bidirectional relation with France, France has a bidirectional relation with Germany but UK is only affecting Italy but not viceversa (Koutmos (1996)).

Explicit cointegration of markets between US, UK, Germany and Japan was studied by Ben-Zion et al. (1996). This was the first study to examine separately the level of the markets and the rates of return separately. In this paper, they also study bond markets of these countries. The researchers come to the conclusion that the only market that is truly cointegrated with the US market is Germany. Chan et al. (1997) was the first study to look at groups of countries such as the European Union, Scandinavian group and Indian subcontinent group. This was the first study to explicitly include some developing countries in their examination. The main problem with their data is that it is monthly.

Atteberry and Swanson (1997) were the first to include Mexico in their study. They found bidirectional causality between Mexico and the US as far back as 1985. Our study goes much further. It includes not just Mexico but all the countries in the Latin American region with stock markets. Our study is therefore the first to look at Argentina, Brazil, Colombia, Chile, Mexico and Venezuela together with the more developed countries. In addition, we study not just bivariate Granger-causality but also block Granger-causality.

The rest of the paper is organized as follows. Next section describes the data and we make some preliminary observations about the characteristics of the data for the 13 countries in our sample. We then discuss the concept of Granger causality along with block Granger causality in a rigorous statistical framework. In the following section, we apply the methodology to our dataset. We discuss the results. Finally, we draw some conclusions

\section{Data and methodology}

The data come from the Bloomberg daily datasets available online. To preserve the flavor of the study from the point of view of a US investor, we convert every series in US dollars. The data run from the beginning of January 1994 through the end of May of 1998. To illustrate, we have included the stock market index over the relevant range for Mexico. Note the large drop (in US dollar terms) of the Mexican market during the end of 1994. We include the following 
Latin American countries for which the data are available for the range of timeperiod of study: Argentina, Brazil, Colombia, Chile, Mexico and Venezuela. In addition, we include the following developed countries: US, Canada, UK, France, Germany, Italy and Japan. The idea is to use a group proxy for North America (excluding Mexico), a group proxy for Europe and a proxy for Asia.

Figure 1. Mexican Stock Market Behavior.

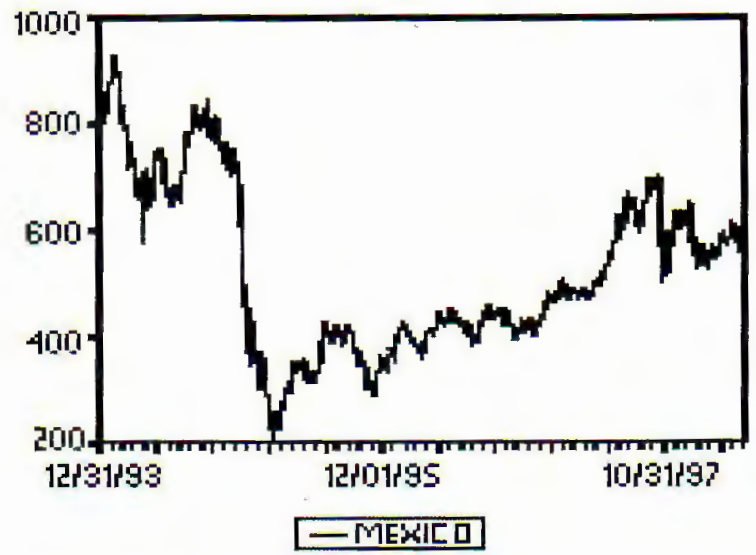

We use two types of unit root tests. The first is the Philips-Perron (1988) test. The test is well suited for analyzing time series whose differences may follow mixed ARMA (p,q) processes of unknown order in that the test statistic incorporates a nonparametric allowance for serial correlation. Consider the following equation:

$$
y_{t}=\tilde{c}_{0}+\tilde{c}_{1} y_{t-1}+\tilde{c}_{2}(t-T / 2)+v_{t},
$$

where $\left\{y_{t}\right\}$ is the relevant time series in equation (1), $T$ is the number of observations and $v_{t}$ is the error term. The null hypothesis of a unit root is $H_{0}: \tilde{c}_{1}=1$. We can drop the trend term to test the stationarity of a variable without the trend. The second test is an augmented Dickey-Fuller (ADF) test which is an extension of the Dickey-Fuller test (see Dickey and Fuller (1979) and (1981)). The ADF test entails estimating the following regression equation (with an autoregressive process):

$$
\Delta y_{t}=c_{1}+\omega y_{t-1}+c_{2} t+\sum_{i=1}^{\rho} d_{i} \Delta y_{t-1}+v_{t} .
$$

In (2), $\left\{y_{t}\right\}$ is the relevant time series, $\Delta$ is a first-difference operator, $t$ is a linear trend and $v_{t}$ is the error term. The above equation can also be estimated without including a trend term (by deleting the term $c_{2} t$ in the above equation). The null hypothesis of the existence of a unit root is $H_{0}: \omega=0$.

Unit root test results: Almost all the countries show that there is a unit root for each time series of prices (see Table 1). However, only a few show 
unit roots in the differenced series (interpreted as the rate of returns series). Therefore, it allows us to investigate the question of cointegration between and among various time series.

Table 1. Unit Root Test Results.

\begin{tabular}{|c|c|c|c|c|}
\hline Country & & Intercept & Trend/Int & None \\
\hline Germany & Ln Price & 1.137928 & -1.801154 & $2.774254^{*}$ \\
& $\Delta$ Ln Price & $-16.47360^{*}$ & $-16.57721^{*}$ & $-16.18442^{*}$ \\
\hline Argentina & Ln Price & -1.755855 & -2.253964 & -0.063564 \\
& $\Delta$ Ln Price & $-15.86320^{*}$ & $-15.85946^{*}$ & $-15.87024^{*}$ \\
\hline Brazil & Ln Price & -1.556117 & -2.576493 & 0.769271 \\
& $\Delta$ Ln Price & $-16.87788^{*}$ & $-16.87096^{*}$ & $-16.85849^{*}$ \\
\hline Canada & Ln Price & 0.076307 & -3.114415 & 1.536945 \\
& $\Delta$ Ln Price & $-15.65603^{*}$ & $-15.71251^{*}$ & $-15.56292^{*}$ \\
\hline Chile & Ln Price & -1.307995 & -1.501435 & -0.151969 \\
& $\Delta$ Ln Price & $-14.25848^{*}$ & $-14.46783^{*}$ & $-14.26460^{*}$ \\
\hline Colombia & Ln Price & -1.586029 & -1.636583 & -1.477302 \\
& $\Delta$ Ln Price & $-15.91731^{*}$ & $-15.91026^{*}$ & $-15.91355^{*}$ \\
\hline US & Ln Price & 0.759042 & -3.186917 & $3.472143^{*}$ \\
& $\Delta$ Ln Price & $-17.38759^{*}$ & $-17.46600^{*}$ & $-16.89660^{*}$ \\
\hline France & Ln Price & 1.144171 & -1.241011 & 1.707038 \\
& $\Delta$ Ln Price & $-16.31955^{*}$ & $-16.49725^{*}$ & $-16.22257^{*}$ \\
\hline UK & Ln Price & 0.811612 & -2.752923 & $2.422446^{*}$ \\
& $\Delta$ Ln Price & $-16.92280^{*}$ & $-17.05832^{*}$ & $-16.69802^{*}$ \\
\hline Italy & Ln Price & 0.099743 & -0.723117 & -1.397619 \\
& $\Delta$ Ln Price & $-15.75406^{*}$ & $-15.80810^{*}$ & $-15.66770^{*}$ \\
\hline Japan & Ln Price & -0.335925 & -1.926766 & -0.746990 \\
& $\Delta$ Ln Price & $-15.41104^{*}$ & $-15.52102^{*}$ & $-15.39489^{*}$ \\
\hline Mexico & Ln Price & -2.032751 & -2.830576 & -0.680023 \\
& $\Delta$ Ln Price & $-14.42241^{*}$ & $-14.46290^{*}$ & $-14.41656^{*}$ \\
\hline Venezuela & Ln Price & 0.759042 & -0.927679 & 1.881973 \\
& $\Delta$ Ln Price & $-13.32603^{*}$ & $-13.33815^{*}$ & $-13.16034^{*}$ \\
\hline
\end{tabular}

* $=$ significant at $5 \%$

The concept of cointegration was proposed by Granger (1981). Engle and Granger (1987) provided an axiomatic foundation of the methodology. Two (or more) $\mathrm{I}(1)$ variables are said to be cointegrated if there exists a linear combination of them that is stationary. Engle and Granger show that if the variables are cointegrated, then the OLS method gives super-consistent estimates. We use the Johansen-Juselius (see Johansen (1988) and Johansen and Juselius (1990) for details) tests for cointegration. The method can be shown to have the error correction representation of the $\operatorname{VAR}(\mathrm{p})$ model with Gaussian errors:

$$
\Delta Z_{t}=a_{0}+\Gamma_{1} \Delta Z_{t-1}+\Gamma_{2} \Delta Z_{t-2}+\ldots+\Gamma_{p-1} \Delta Z_{t-p+1}+\Pi Z_{t-p}+B X_{t}+u_{t},
$$


where $Z_{t}$ is a an $m \times 1$ vector of $I(1)$ variables, $X_{t}$ is an $s \times 1$ vector of $I(0)$ variables, $\Gamma_{1}, \Gamma_{2}, \Gamma_{p-1}, \Pi$ are $m \times m$ matrices of unknown parameters, $B$ is an m×s matrix and $u_{t} \sim N(0, \Sigma)$. The maximum likelihood method is used to estimate (3) subject to the hypothesis that $\Pi$ has a reduced rank, $r<m$. The hypothesis, therefore, is as follows:

$$
H(r): \Pi=\alpha \beta^{\prime}
$$

where $\alpha$ and $\beta$ are $\mathrm{m} \times \mathrm{r}$ matrices. If certain conditions are fulfilled, equation (4) implies that the process $\Delta Z_{t}$ is stationary, $Z_{t}$ is non-stationary, and that $\beta Z_{t}$ is stationary. The values of $\beta Z_{t}$ are known as the cointegrating relations and $\beta$ the cointegrating vector. In our model $C_{t}$ plays the role of $Z_{t}$ in (12). If we find that the two series are cointegrated, the relevant hypothesis for the vector $\beta$ to be tested is $H_{0}: \beta^{\prime}=(1,-1)$. Our results, however, have to be interpreted with caution. The unit root tests have low power. The same goes for the Johansen-Juselius cointegration tests.

\section{Exogeneity and Granger causality}

The Granger approach to the question whether $\mathbf{x}_{t}$ causes $\mathbf{y}_{t}$ is to see how much of the current $\mathbf{y}$ can be explained by past values of $\mathbf{y}$ and then to see whether adding lagged values of $\mathbf{x}$ can improve the explanation. The variable $\mathbf{y}$ is said to be Granger-caused by $\mathbf{x}$ if $\mathbf{x}$ helps in the prediction of $\mathbf{y}$, or equivalently if the coefficients on the lagged $\mathbf{x s}$ are statistically significant. It is important to note that the statement " $\mathbf{x}_{t}$ Granger-causes $\mathbf{y}_{t}$ " does not imply that $\mathbf{y}_{t}$ is the effect or the result of $\mathbf{x}_{t}$. Granger causality measures precedence and information content but does not by itself indicate causality in the more common use of the term.

We have made the assumption that $\mathbf{y}_{t}$ is a function of past values of itself and present and past values of $\mathbf{x}_{t}$. Моге precisely, we assume that $\mathbf{x}_{t}$ is weakly exogenous: the stochastic structure of $\mathbf{x}_{t}$ contains no information that is relevant for the estimation of the parameters of interest, $\mathbf{B}$ and $\boldsymbol{\Omega}$. Formally, $\mathbf{x}_{t}$ will be weakly exogenous if, when the joint distribution of $\mathbf{z}_{t}=\left(\mathbf{y}_{\mathbf{t}}, \mathbf{x}_{t}\right)$, conditional on the past, is factorized as the conditional distribution of $\mathbf{y}_{t}$ given $\mathbf{x}_{t}$, times the marginal distribution of $x_{t}$; and the next two points must happen:(a) the parameters of these conditional and marginal distributions are not subject to cross-restrictions, and (b) the parameters of interest can be uniquely determined from the parameters of the conditional model alone. Under these conditions $\mathbf{x}_{t}$ may be treated "as if" it were determined outside the conditional model for $y_{t}$. Because it is a condition on parameters, rather than a restriction on joint probability distributions, it is usual to treat weak exogeneity as a non-directly testable assumption, although there are possible ways in which the assumption can be tested indirectly. This can be expressed in the next definition:

Let $F(A \mid B)$ the conditional distribution of $A$ given $B$, and let $\Omega_{t}$ the set of information at time $t$ (including past values of $\mathbf{y}_{t}$ and $\left.\mathbf{x}_{t}\right)$. If $F\left(\mathbf{y}_{t+j}\right)$ $\left.\Omega_{t}\right)=F\left(\mathbf{y}_{t+j} \mid \Omega_{t}-X_{t}\right) \forall_{j} \geq 0$, is said that $X$ does not Granger-cause $Y$ with 
respect of the set of information $\boldsymbol{\Omega}_{t}$. If this relation does not occur is said that $X$ Granger-causes $Y$.

While the weak exogeneity of $\mathbf{x}_{t}$ allows efficient estimation of $\mathbf{B}$ and $\boldsymbol{\Omega}$ without any reference to the stochastic structure of $\mathbf{x}_{t}$, the marginal distribution of $\mathbf{x}_{t}$, while not containing $\mathbf{y}_{t}$, will contain $\mathbf{Y}_{t-1}^{0}=\left(\mathbf{y}_{t-1}, \mathbf{y}_{t-2}, \cdots, \mathbf{y}_{1}\right)$, and the possible presence of lagged $\mathbf{y}_{t} s$ can lead to problems when attempting to predict $\mathbf{y}_{t}$. In order to be able to treat the $\mathbf{x}_{t}$ as given when predicting $\mathbf{y}_{t}$, we need to ensure that no feedback exists from $\mathbf{Y}_{t-1}^{0}$ to $\mathbf{x}_{t}$ : the absence of such feedback is equivalent to the statement that $\mathbf{y}_{t}$ does not Granger-cause $\mathbf{x}_{t}$. Weak exogeneity supplemented with Granger non-causality is called strong exogeneity.

Unlike weak exogeneity, Granger non-causality is directly testable. To investigate such tests, and to relate Granger non-causality to yet another concept of exogeneity, we need to introduce the dynamic structural equation model and the vector autoregressive process (VAR). The dynamic structural equation model extends the multivariate regression model in two directions: first, by allowing simultaneity between the endogenous variables in $\mathbf{y}_{t}$ and, second, explicitly considering the process generating the exogenous variables $\mathbf{x}_{t}$. We thus have

$$
\mathbf{A}_{0} \mathbf{y}_{t}=\sum_{i=1}^{m} \mathbf{A}_{i}^{\prime} \mathbf{y}_{t-i}+\sum_{i=0}^{m} \mathbf{B}_{i}^{\prime} \mathbf{x}_{t-i}+\varepsilon_{1 t}
$$

and

$$
\mathbf{x}_{t}=\sum_{i=1}^{m} \mathbf{C}_{i}^{\prime} \mathbf{x}_{t-i}+\varepsilon_{2 t}
$$

The simultaneity of the model is a consequence of $\mathbf{A}_{0} \neq \mathbf{I}_{N}$. The errors $\varepsilon_{1 t}$ and $\varepsilon_{2 t}$ are assumed to be jointly independent processes, which could be serially correlated but will be assumed here to be white noise, and intercept vectors are omitted for simplicity. Equation (6) shows that $\mathbf{x}_{t}$ is generated by an $m$ th order VAR process, in which current values of $\mathbf{x}$ are functions of $m$ past values of $\mathbf{x}$ only.

If, in the model $(5), \mathrm{E}\left(\varepsilon_{1 t} \mathbf{x}_{t-s}\right)=0$ for all $\mathrm{s}, \mathbf{x}_{t}$ is said to be strictly exogenous. Strict exogeneity is useful because no information is lost by limiting attention to conditional distributions on $\mathbf{x}_{t}$, which will usually result in considerable simplifications in statistical inference. A related concept is that of a variable being predetermined: a variable is predetermined if all its current and past values are independent of the current error $\epsilon_{1 t}$. If $\mathbf{x}_{t}$ is strictly exogenous, then it will also be predetermined, while if $\mathrm{E}\left(\epsilon_{1 t} \mathbf{y}_{t-s}\right)=0$, for $s>0$, then $\mathbf{y}_{t-s}$ will be predetermined as well.

In many cases, strictly exogenous variables will also be weakly exogenous in the dynamic structural equation models, although one important class of exceptions is provided by rational expectations variables, in which behavioural 
parameters are generally linked to the distributions of exogenous variables. Similarly, predetermined variables will usually be weakly exogenous, except again in the case where there are cross-restrictions between behavioural parameters and the parameters of the distribution of the predetermined variables.

Strict exogeneity can be tested in dynamic structural equation models by using the final form, in which each endogenous variable is expressed as an infinite distributed lag of the exogenous variables

$$
\mathbf{y}_{t}=\sum_{i=0}^{\infty} \mathbf{J}_{i} \mathbf{x}_{t-1}+\mathbf{e}_{t}
$$

where the $\mathbf{J}_{i}$ matrices are functions of the $\mathbf{A}_{i} s$ and $\mathbf{B}_{i} s$, and where $\mathbf{e}_{t}$ is a stochastic process possessing a VAR representation and having the property that $\mathrm{E}\left(\mathbf{e}_{t} \mathbf{x}_{t-s}^{\prime}\right)=0$ for all $s$.

Strict exogeneity is intimately related to Granger non-causality. Indeed, the two tests for strict exogeneity of $\mathbf{x}_{t}$ can also be regarded as tests for $\mathbf{y}_{t}$ not Granger-causing $\mathbf{x}_{t}$. The two concepts are not equivalent, however. If $\mathbf{x}_{t}$ is strictly exogenous in the model (5), then $\mathbf{y}_{t}$ does not Granger-cause $\mathbf{x}_{t}$, where $\mathbf{y}_{t}$ is endogenous in that model. However, if $\mathbf{y}_{t}$ does not Granger-cause $\mathbf{x}_{t}$, then there exists a dynamic structural equation model with $\mathbf{y}_{t}$ endogenous and $\mathbf{x}_{t}$ strictly exogenous, in this sense that there will exist systems of equations formally similar to (5). This implies that tests for the absence of a causal ordering can be used to refute the strict exogeneity specification in a given dynamic structural equation model, but such tests cannot be used to establish it.

Statistical inference may be carried out conditionally on a subset of variables that are not strictly exogenous: all that we require is that they be weakly exogenous. Thus, unidirectional Granger causality is neither necessary nor sufficient for inference to proceed conditional on a subset of variables.

\section{Tests of exogeinity and Granger causality}

To develop operational test of Granger causality and strict exogeneity, consider the $g=n+k$ dimensional vector $\mathbf{z}_{t}=\left(\mathbf{y}_{t}, \mathbf{x}_{t}\right)$, which we assume has the following $m$ th order VAR representation

$$
\mathbf{z}_{t}=\sum_{i=1}^{m} \pi_{i} \mathbf{z}_{t-i}+\mathbf{v}_{t},
$$

where

$$
\begin{gathered}
\mathrm{E}(\mathbf{v})_{t}=\mathrm{E}\left(\mathbf{v}_{t} \mid \mathbf{Z}_{t-1}^{0}\right)=0, \\
\mathrm{E}\left(\mathbf{v}_{t} \mathbf{v}_{s}^{\prime}\right)=\mathrm{E}\left\{\mathrm{E}\left[\mathbf{v}_{t} \mathbf{v}_{s}^{\prime} \mid \mathbf{Z}_{t-1}^{0}\right]\right\}=\left\{\begin{array}{ccc}
\sum_{v} & \text { if } & t=s, \\
0 & \text { if } & t \neq s,
\end{array}\right.
\end{gathered}
$$


and

$$
\mathbf{z}_{t-1}^{0}=\left(\mathbf{z}_{t-1}, \mathbf{z}_{t-2}, \ldots, \mathbf{z}_{1}\right)
$$

The VAR equation ( 7 ) can be partitioned as

$$
\begin{aligned}
& y_{t}=\sum_{i=1}^{m} C_{2 i} X_{t-1}+\sum_{i=1}^{m} D_{2 i} y_{t-i}+v_{1 t} \\
& X_{t}=\sum_{i=1}^{m} \mathrm{E}_{2 i} X_{t-i}+\sum_{i=1}^{m} \mathrm{~F}_{2 i} y_{t-i}+v_{2 t}
\end{aligned}
$$

where $\mathbf{v}_{t}^{\prime}=\left(\mathbf{v}_{1 t}^{\prime} \mathbf{v}_{2 t}^{\prime}\right)$, and where $\Sigma_{v}$ is correspondingly partitioned as

$$
\sum_{v}=\left(\begin{array}{ll}
\sum_{11} & \sum_{12} \\
\sum_{12} & \sum_{22}
\end{array}\right)
$$

Here $\sum_{i j}=\mathrm{E}\left(v_{i t} v_{j t}^{\prime}\right), i, j=1,2$ so that, although the error vectors $\mathbf{v}_{1 t} \mathbf{v}_{2 t}$ are each serially uncorrelated, they can be correlated with each other contemporaneously, although at no other lag. Given equations (8) and (9), y does not Granger-cause $\mathbf{x}$ if, and only if, $F_{2 i}=0$, for all $i$. An equivalent statement of this proposition is that $\left|\Sigma_{22}\right|=\left|\Sigma_{2}\right|$, where $\sigma_{2}=\mathrm{E}\left(w_{2 t}, w_{2 t}^{\prime}\right)$ obtained form the restricted regression

$$
x_{t}=\sum_{i=1}^{m} \mathrm{E}_{1 i} x_{t-1}+w_{2 t} .
$$

Similarly, $\mathbf{x}$ does not Granger-cause $\mathbf{y}$ if, and only if, $C_{2 i} \equiv 0$ for all $i$ or, equivalently, that $\left|\Sigma_{11}\right|=\left|\Sigma_{1}\right|$, where $\Sigma_{1}=\mathrm{E}\left(w_{1 t}, w_{1 t}^{\prime}\right)$ obtained from the regression

$$
y_{t}=\sum_{i=1}^{m} C_{1 i} y_{t-1}+w_{1 t} .
$$

If the system (8)-(9) is multiplied by the matrix

$$
\left(\begin{array}{cc}
I_{n} & -\sum_{12} \sum_{22}^{-1} \\
-\sum_{12}^{\prime} \sum_{11}^{-1} & I_{n}
\end{array}\right)
$$

then the first $n$ equations of the new system can be written as

$$
y_{t}=\sum_{i=1}^{m} C_{3 i} x_{t-i}+\sum_{i=1}^{m} D_{3 i} y_{t-1}+\omega_{1 t}
$$

where the error $\omega_{1 t}=v_{1 t}-\Sigma_{12} \Sigma_{22}^{-1} v_{2 t}$, since it is uncorrelated with $v_{2 t}$, is also uncorrelated with $\mathbf{x}_{t}$. Similarly, the last $k$ equations can be written as

$$
x_{i}=\sum_{i=1}^{m} \mathrm{E}_{3 i} x_{t-1}+\sum_{i=1}^{m} F_{3 i} y_{t-i}+\omega_{2 t} .
$$


Denoting $\Sigma_{\omega 1}=\mathrm{E}\left(\omega_{i t}\right), \omega_{i t}^{\prime}, i=1,2$, there is instantaneous causality between $\mathbf{y}$ and $\mathbf{x}$ if, and only if, $C_{30} \neq 0$ and $\mathrm{E}_{30} \neq 0$ or, equivalently, $\left|\Sigma_{11}\right|>\left|\Sigma_{\omega 1}\right|$ and $\left|\Sigma_{22}\right|>\Sigma_{\omega 2} \mid$. Given this framework, a measure of linear feedback from $\mathbf{y}$ to $\mathrm{x}$ is defined as

$$
F_{y \rightarrow x}=\ln \left[\frac{\left|\sum_{2}\right|}{\left|\sum_{22}\right|}\right]
$$

so that the statement "y does not cause $\mathbf{x}$ " is equivalent to $F_{y \rightarrow x}=0$. Symmetrically, $\mathbf{x}$ does not cause $\mathbf{y}$ if, and only if, the measure of linear feedback from $\mathbf{x}$ to $\mathbf{y}$,

$$
F_{x \rightarrow y}=\ln \left[\frac{\left|\sum_{1}\right|}{\sum_{11}}\right]
$$

is zero. The existence of instantaneous causality between $\mathbf{y}$ and $\mathbf{x}$ amounts to a non-zero measure of linear feedback

$$
F_{x \rightarrow y}=\ln \left[\frac{\left|\sum_{11}\right|}{\left|\sum_{\omega 1}\right|}\right]=\ln \left[\frac{\left|\sum_{22}\right|}{\left|\sum_{\omega 2}\right|}\right] .
$$

A concept closely related to the idea of linear feedback is that of linear dependence, a measure which is given by

$$
F_{x \rightarrow y}=\ln \left[\frac{\left|\sum_{1}\right|}{\left|\sum_{\omega 1}\right|}\right]=\ln \left[\frac{\left|\sum_{2}\right|}{\left|\sum_{\omega 2}\right|}\right] .
$$

From these measures it is easily seen that $F_{x, y}=F_{y \rightarrow x}+F_{x \rightarrow y}+F_{x . y}$, so that linear dependence can be composed additively into the three forms of feedback. Absence of a particular causal ordering is then equivalent to one of these feedback measures being zero.

To obtain estimates of these measures, we shall suppose that each of the regressions (8)-(13) have been estimated by LS and the following matrices formed

$$
\begin{aligned}
& \widehat{\sum_{i}}=(T-m)^{-1} \sum_{t=m+1}^{T} \hat{w}_{i t} \hat{w}_{i t}^{\prime}, \\
& \widehat{\sum}_{i i}=(T-m)^{-1} \sum_{t=m+1}^{T} \hat{v}_{i t} \hat{v}_{i t}^{\prime}, \\
& \widehat{\sum}_{\omega i}(T-m)^{-1} \sum_{t=m+1}^{T} \hat{\omega}_{i t} \hat{\omega}_{i t}^{\prime},
\end{aligned}
$$

for $i=1,2$, where $\hat{w}_{i t}$ is the vector of LS residuals corresponding to the error vector $w_{i t}$, similarly for $\hat{v}_{i t}$ and $\hat{\omega}_{i t}$. From these estimates we can then compute the various feedback measures. 
It then follows that the LR test statistic of the null hypothesis $H_{01}: F_{y \rightarrow x}=$ 0 ( $\mathbf{y}$ does not Granger-cause $\mathbf{x}$ ) is

$$
L R:(T-m) \hat{F}_{y \rightarrow x} \sim \chi_{n k m}^{2} .
$$

Similarly, the null $H_{02}: F_{x \rightarrow y}=0$ is tested by $(T-m) \hat{F}_{x \rightarrow y} \sim \chi_{n k m}^{2}$, and $H_{03}=F_{x, y}=0$ by $(T-m)=\hat{F}_{x . y} \sim \chi_{n k}^{2}$.

Since these are tests of nested hypotheses, $\hat{F}_{y \rightarrow x}, \hat{F}_{x \rightarrow y}$ and $\hat{F}_{x, y}$ are asymptotically independent. All three restrictions can be tested at once since $(T-m) \hat{F}_{x, y} \chi_{n k(2 m+1)}$ on $H_{04}: F_{x, y}=0$.

The corresponding Wald and LM statistics testing, for example, $H_{01}$ : $F_{y \rightarrow x}=0$ are

$$
\begin{aligned}
& W:(T-m)\left[\operatorname{tr}\left(\widehat{\sum_{2} \widehat{\sum}_{22}^{-1}}\right)-n\right] \sim \chi_{n k m}^{2} \\
& L M:(T-m)\left[n-\operatorname{tr}\left(\widehat{\sum_{22}} \widehat{\sum}_{2}^{-1}\right)\right] \sim \chi_{n k m}^{2},
\end{aligned}
$$

respectively. The $95 \%$ confidence interval $F_{y \rightarrow x}$, and is given by

$$
\left[\hat{A}_{y \rightarrow x}, \hat{B}_{y \rightarrow x}\right]
$$

where

$$
\hat{A}_{y \rightarrow x}=\left[\left(\hat{F}_{y \rightarrow}-\frac{n k m-1}{3(T-m)}\right)^{\frac{1}{2}}-\frac{1.96}{\sqrt{T-m}}\right]^{2}-\frac{2 n k m+1}{3(T-m)}
$$

and

$$
\hat{B}_{y \rightarrow x}=\left[\left(\hat{F}_{y \rightarrow-}-\frac{n k m-1}{3(T-m)}\right)^{\frac{1}{2}}+\frac{1.96}{\sqrt{T-m}}\right]^{2}-\frac{2 n k m+1}{3(T-m)}
$$

Similarly, the tests statistics and confidence intervals can be constructed for the hypotheses $F_{x \rightarrow y}$ and $F_{x . y}$. 


\section{Results}

Let us call the stock price index as $(P I)_{i}$. We study $\ln (P I)_{i}$ and $\Delta \ln (P I)_{i}$ among different values of $i . \Delta \ln (P I)_{i}$ measures rate of return. We run two sets of tests: (1) Granger causality between series and cointegration between series. Results of pairwise tests are reported here.

The following table shows results from bivariate cointegration. It shows that Germany is cointegrated with UK. Argentina is cointegrated with Canada. Curiously, Brazil is not cointegrated with any country. Canada is cointegrated with Argentina, Chile, Colombia, UK, Japan and Mexico. Chile is cointegrated with Canada, US and UK. Colombia is cointegrated with Canada only. Note that it makes no sense to talk about cointegration of differenced series because they do not have unit roots.

There is bidirectional causality in the $\log$ price series as well as in the rates of return series for the following countries: Germany and Argentina, Germany and France, Argentina and France, Canada and France, Canada and the UK, Italy and Mexico. The following countries only have bidirectional causality in the log price series (and not in the rates of return series): Germany and Chile, Argentina and the UK, Chile and the UK, France and Japan.

On the other hand, the following countries show bidirectional causality only in the rate of return series: Argentina and Brazil, Brazil and Chile, Canada and Chile, US and France, France and Mexico.

Unidirectional causality is found in the following for both series (that is, for the price level and for the rate of return series): Germany is Granger causally prior to Italy (but not viceversa), Brazil is Granger causally prior to Germany, Canada is Granger causally prior to Germany, US is Granger causally prior to Germany, UK is Granger causally prior to Germany, Mexico is Granger causally prior to Germany, Argentina is Granger causally prior to Chile, Argentina is Granger causally prior to Italy, Argentina is Granger causally prior to Japan, Mexico is Granger causally prior to Argentina, Brazil is Granger causally prior to France, Brazil is Granger causally prior to UK, Brazil is Granger causally prior to Italy, Brazil is Granger causally prior to Japan, Canada is Granger causally prior to Brazil, Colombia is Granger causally prior to Brazil, Mexico is Granger causally prior to Brazil, Canada is Granger causally prior to Italy, Canada is Granger causally prior to Japan, US is Granger causally prior to Canada, Colombia is Granger causally prior to Chile, US is Granger causally prior to Chile, Italy is Granger causally prior to Chile, Japan is Granger causally prior to Chile, Mexico is Granger causally prior to Chile, Colombia is Granger causally prior to Venezuela, Italy is Granger causally prior to Colombia, Mexico is Granger causally prior to Colombia, US is Granger causally prior to UK, US is Granger causally prior to Italy, US is Granger causally prior to Japan, US is Granger causally prior to Venezuela, Japan is Granger causally prior to Italy, UK is Granger causally prior to Japan, Mexico is Granger causally prior to Japan. 
Table 2. Cointegration Test Results for 13 Countries

\begin{tabular}{|c|c|c|c|c|c|c|c|c|c|c|c|c|c|}
\hline & GER & ARG & BRA & $\mathrm{CAN}$ & CHIL & $\mathrm{COL}$ & US & FRA & UK & ITA & JAP & MEX & VEN \\
\hline GER & & 9.17 & 9.79 & 18.68 & 14.14 & 7.26 & 23.09 & 23.85 & $30.79 *$ & 17.19 & 18.87 & 10.79 & 7.08 \\
\hline $\mathrm{ARG}$ & & & 20.30 & $20.48 *$ & 17.41 & 23.65 & 20.64 & 11.72 & 19.08 & 11.84 & 18.76 & 14.93 & 13.65 \\
\hline BRA & & & & 22.42 & 13.64 & 4.20 & 19.41 & 11.78 & 19.76 & 9.44 & 18.59 & 13.19 & 10.48 \\
\hline $\mathrm{CAN}$ & & $*$ & & & $25.45 *$ & $30.43 *$ & 23.21 & 18.54 & $25.59 *$ & 21.95 & $28.25 *$ & $27.28 *$ & 19.44 \\
\hline CHIL & & & & * & & 8.29 & $26.05 *$ & 20.95 & $26.45 *$ & 22.19 & 16.18 & 20.03 & 7.33 \\
\hline $\mathrm{COL}$ & & & & * & & & 20.04 & 9.26 & 22.12 & 7.19 & 12.51 & 17.06 & 20.28 \\
\hline US & & & & & $*$ & & & 21.23 & $29.39 *$ & $26.10 *$ & $27.99 *$ & $24.29 *$ & 18.07 \\
\hline FRA & & & & & & & & & 26.02 * & 22.57 & 20.59 & 10.66 & 11.35 \\
\hline UK & $*$ & & & $*$ & $*$ & & * & $*$ & & $30.48 *$ & $32.39 *$ & 20.54 & 16.57 \\
\hline ITA & & & & & & & * & & * & & 18.38 & 11.29 & 9.76 \\
\hline $\mathrm{JAP}$ & & & & * & & & $*$ & & $*$ & & & 18.856 & 18.91 \\
\hline MEX & & & & * & & & & & & & & & 12.93 \\
\hline VEN & & & & & & & & & & & & & \\
\hline
\end{tabular}

* = significant at $5 \%$ 
The following countries have unidirectional causality only in levels of stock market indexes: Japan is Granger causally prior to Germany, Canada is Granger causally prior to Argentina, France is Granger causally prior to UK, France is Granger causally prior to Italy, Mexico is Granger causally prior to UK.

The relation Canada is Granger causally prior to Venezuela is present only for rate of return series. This analysis confirms that Mexico does have impact (for both series) for all countries except for US, Canada and Venezuela. On the other hand, Mexico is only affected broadly by France and Italy. The other important result is that the US market is not affected by any other country. On the other hand, the only countries that are not affected by the US are Argentina, Brazil, Colombia, Mexico and Venezuela. To put it differently, the only Latin American country affected by the US market is Chile.

This analysis is incomplete. The causality tests above only relate to bivariate relationships. We need to explore multivariate relationships to see what exactly is going on. For example, the fact that US does not affect Mexico does not necessarily mean that US and Canada together does not affect Mexico. Since our interest here lies in Latin America, we restrict our attention only to groups of countries affecting Latin American countries as a group or individual Latin American countries. The effects of other groups of countries affecting Latin America (as a whole) are shown in Table 3. All of them are significant. Therefore, we conclude that Latin American countries as group is influenced by all the developed countries.

Table 3. Multivariate Granger Causality: Blocks of Countries affecting Latin America.

\begin{tabular}{|c|c|c|}
\hline$H_{0}:$ "(Block)" does not affect & \multicolumn{2}{|c|}{$p$ value } \\
\hline Latin America & Log Price & Log Price \\
\hline US-Canada & $0.016^{*}$ & $0.000^{*}$ \\
\hline Europe & $0.000^{*}$ & $0.000^{*}$ \\
\hline Japan & $0.001^{*}$ & $0.004^{*}$ \\
\hline Europe-US-Canada & $0.000^{*}$ & $0.003^{*}$ \\
\hline Europe-Japan & $0.000^{*}$ & $0.000^{*}$ \\
\hline All developed countries & $0.000^{*}$ & $0.000^{*}$ \\
\hline
\end{tabular}

* = significant at $5 \%$

Given the conclusion that the Latin American countries as a group are affected by the developed world, the following question arises: What can we say about groups of countries affecting each country of Latin America singly? 
The results of this exercise are shown in Table 4.

Table 4. Blocks of Countries affecting specific Latin America Country.

\begin{tabular}{|c|c|c|c|}
\hline \multicolumn{2}{|c|}{ Block affecting specific country } & \multicolumn{2}{|c|}{$p$-value } \\
\hline Country & Block & Log Price & $\Delta$ Log Price \\
\hline \multirow[t]{7}{*}{ Argentina } & Latin America & $0.000^{*}$ & $0.000^{*}$ \\
\hline & US-Canada & 0.244 & 0.393 \\
\hline & Europe & $0.000^{*}$ & $0.000^{*}$ \\
\hline & Europe - US-Canada & $0.000^{*}$ & 0.203 \\
\hline & US-Canada-Japan & $0.000^{*}$ & 0.091 \\
\hline & Europe-Japan & $0.000^{*}$ & $0.048^{*}$ \\
\hline & Europe-US-Can-Japan & $0.000^{*}$ & 0.087 \\
\hline \multirow[t]{7}{*}{ Brazil } & Latin America & $0.002^{*}$ & $0.001^{*}$ \\
\hline & US-Canada & 0.105 & $0 . \overline{290}$ \\
\hline & Europe & 0.020 & $0.004^{*}$ \\
\hline & Europe-US-Canada & $0.000^{*}$ & $0.001^{*}$ \\
\hline & US-Canada-Japan & $0.000^{*}$ & 0.060 \\
\hline & Europe-Japan & $0.000^{*}$ & $0.007^{*}$ \\
\hline & Europe-US-Can1-Japan & $0.000^{*}$ & $0.001^{*}$ \\
\hline \multirow[t]{7}{*}{ Chile } & Latin America & $0.000^{*}$ & $0.000^{*}$ \\
\hline & US-Canada & 0.058 & 0.087 \\
\hline & Europe & $0.000^{*}$ & $0.001^{*}$ \\
\hline & Europe-US-Canada & $0.000^{*}$ & $0.001^{*}$ \\
\hline & US-Canada-Japan & $0.000^{*}$ & $0.000^{*}$ \\
\hline & Europe-Japan & $0.000^{*}$ & $0.000^{*}$ \\
\hline & Europe-US-Can1-Japan & $0.000^{*}$ & $0.000^{*}$ \\
\hline \multirow[t]{7}{*}{ Mexico } & Latin America & $0.019^{*}$ & $0.101^{*}$ \\
\hline & US-Canada & 0.160 & 0.373 \\
\hline & Europe & $0.013^{*}$ & $0.012 *$ \\
\hline & Europe-US-Canada & $0.000^{*}$ & 0.088 \\
\hline & US-Canada-Japan & $0.000^{*}$ & 0.378 \\
\hline & Europe-Japan & $0.000^{*}$ & 0.052 \\
\hline & Europe-US-Can-Japan & $0.000^{*}$ & 0.087 \\
\hline
\end{tabular}

$*^{*}=$ significance at $5 \%$

Since Colombia and Venezuela do not show any influence from the "outside", we exclude them from this analysis. From the table above, one pattern emerges very clearly: US and Canada do not have a cause and effect relationship with the Latin American market either from the stock price level or from the rate of return level. This conclusion flies in the face of common perceptions of many people. 


\section{Conclusions}

There are very many surprises in the result. The causality typically does not flow the way we normally come to expect it to flow. We do not find US-Canada as a group, having a large Granger causality effect on any of the Latin American countries including Mexico. The strong absence of the effects of the US and Canada is surprising in the light of NAFTA. We would have expected a large NAFTA effect as Mexico depends so much on the US in terms of its trade.

From the point of view of an investor in the US, this is good news. It tells the investor that despite NAFTA, there is a good deal to be gained by diversifying investment in Latin America in general and Mexico in particular. Among the Latin American countries, Venezuela seems to be a complete outlier. Neither it is affected by any country nor does it affect any other. This result is also surprising. Again, the benefits of diversification for the US investor are obvious. From similar studies of Asian countries, we know that there have been much more integration of the stock markets with US and Canada (with notable exception of India). Latin America surprisingly has not gone down that path till the end of 1998. Since then, presumably there has been much more integration between the economies of the United States and Canada with the rest of Latin America (specially Mexico). Thus, one obvious extension of this study would be to include more recent data to see what has happened in the new century.

Results of Granger causality always have to be interpreted carefully. Even though we have used the phrase "is Granger causally prior to" rather liberally, the Granger test does not resolve the question of whether this form of "causality" should be used to interpret common cause and effect in terms of logic.

\section{References}

Attenberry, W. L., and P. E. Peggy (1997). Equity Market Integration: The Case of North America, North American Journal of Economics Finance, 8, pp. 23-37.

Bekaert, G., H. Campbell R., and R. Lusmsdaine (1999). Dating the Integration of World Equity Market, paper presented at the American Finance Association Annual Conference in New York.

Ben-Zion, U., J. J. Choi, and S. Hauser (1996). The price linkages between country funds and national stock markets: evidence from cointegration and causality test of Germany, Japan, and UK funds, Joumal of Busuiness Finance \& Accounting, 23(7), pp. 10051017.

Chan, K. C., B. E. Gup, and M. Pan (1997). International stock market efficiency and integration: A study of eighteen nations, Journal Business Finance \& Accounting 24(6) pp. 803-813.

Darbar, S. M., and P. Deb (1997). Co-movements in international equity markets, Journal of Financial Research, (20)3 pp. 305-322.

Dickey, D. A., W. A. Fuller (1979). Distributions of the Estimators for Autoregressive Time Series with a Unit Root. Journal of the American Statiscal Association, 74, pp. 427-31.

Dickey, D. A., and W. A. Fuller (1981). Likelihood Ratio Statistics for Autoregressive Time Series with a Unit Root. Econometrica, 49, pp. 1057-72.

Engle, R. F., and C. W. J. Granger (1987). Cointegration and Error Correction: representation, estimation, and testing, Econometrica, 55, pp. 251-76. 
Granger, C. W. J. (1981). Some Properties of Time Series Data and Their Use in Econometric Model Specification, Journal of Econometrics, 16, pp. 121-30.

Johansen, S. (1988). Statiscal Analysis of Cointegration Vectors, Journal of Economic Dynamics and Control, 12, pp. 231-54.

Johansen, S., and J. Katarina (1990). The Maximum Likelihood Estimation and Inference on Cointegration-with Application to Demand for Money. Oxford Bulletin of Economics and Statistics, 52, pp. 169-210.

Koutmos, G. (1996). Modeling the dynamic interdependence of major European Stock markets, Journal of Business Finance \& Accounting, 23(7) pp. 975-988.

Malliaris, A. G., and J.L. Urrutia (1992). The International Crash of October 1987: Causality Tests, Journal of Financial and Quantitative Analysis 27(3) pp. 353-364.

Najand, M. (1996). A causality test of the October crash of 1987: From Asian stock markets, Journal of Business Finance \& Accounting, 23(3) pp. 439-448. 